\title{
Transport and Environment
}

\author{
M. Mravčíková \& A. Peltrám \\ Institute for European Integration, Banking Collage, Prague, Czech Republic
}

\begin{abstract}
This article compares the impact of road and railway transport on the environment. A great amount of resources of the European Union's funds are assigned for transport and environment. It is necessary to overcome some obstacles for attaining the money, i.e. administrative demands, to have own sufficient funds, to overcome the activities of NGOs and there is also not a satisfactory process of transition to the postindustrial, knowledge-based society of services with a completely changing structure of economics. The influence of the NGO was proved within two studies; the main findings are that NGOs are closely bound with administration and cause problems with information service and secondly that the delay in completion causes economical and environmental losses. The railways have to find the limits of efficiency in passenger transport and freight transport and transform its technical equipment and service to be efficient by all means. We also pointed out that the potential capacity of roads is in general higher than that of the railways with the typical weight of goods trains and liners.
\end{abstract}

KEY WORDS: Road transport, railway transport and environment.

\section{IMPACT OF ROAD AND RAILWAY TRANSPORT ON ENVIRONMENT AND ECONOMY}

As an impletion of the principle of solidarity, the Czech Republic could receive from the European funds about $€ 29.5$ billion during the period 2007-2013. It could receive even more if the Czech Republic would successfully participate in some projects of the $7^{\text {th }}$ frame programme R\&D. To this amount the operational programme "Transport" could participate with $€ 5.574$ billion and with amounts from other operational programmes of nearly $€ 6.4$ billion. Transport, as one of the most important segments of the national economy, could receive nearly $22 \%$. The $2^{\text {nd }}$ highest share of funding is provided for the environment. Transport and environment together could receive support totalling about $42 \%$ of the total sum for co- financing. There have been some prerequisites to reach it:

- To have prepared proposals of projects to the highest quality. This is not easy because one of the hidden conditions is a necessary deep understanding of the basic principles and rules of the European Union - it is not only knowledge of the technical aspects on how to fill in the blank forms of requests, rather to the highly "bureaucratic" rules, as they are often labelled by the Czech VIPs.

- To reach possible support it is necessary to have own funds: in the case of eligible capital costs it is about $15 \%$ of the total amount and the same share falls on capital costs not eligible for co-financing. It is also impossible to eliminate some attempts to decrease own funding on account of co-financed share. 
- To succeed in the preparation of projects it is necessary to deal relatively successfully with some groups of NGOs that regard it as a success to block in fact all major infrastructure projects based on the idea that transport with any negative effects on the environment really does not exist (for example there are no internal combustion engines without greenhouse emissions).

- There is not always a satisfactory awareness that the economy is in a process of transition from the industrial to the post-industrial, knowledge-based society of services with a completely changing structure of economics:

- Decrease of primary products sectors and in the case of energy, a change of structure enabling transmissions, instead of transporting sources of energy, especially solid fossil fuels.

- Decrease of secondary sectors - manufacturing; the share of these industries in the Czech Republic has been twice as high as about one decade earlier in the Member States of EU 15.

- Relatively lower share of services means that in the Czech Republic the process of transition has not yet been fully in accordance with the general trends of postindustrial society.

- Before the start of the financial, and later real economic, crisis within the EU there were: - about 23 million of craft and small- and medium- sized enterprises with the share of the total amount of entrepreneurial entities $98 \%$ to $99 \%$, their share on new employment in the private sector was about $80 \%$, the share of GDP was growing and has reached nearly 50\%; - only about 41000 large enterprises. Due to the recent financial and economic crises, this number should decline. Additionally, the decrease in employment in these sectors shall be, after labour-saving measures, much greater.

\section{DEVELOPMENT OF TRANSPORT INFRASTRUCTURE AND NGOS}

Within the two studies we tried:

- To compare the compliance of transition of the Community law concerning protection of environment according to all aspects of the environmental protection, from the very beginning (intention of investment) up to its implementation.

- The conclusions:

- We found full consent as to the content, but more severe conditions for the public administration to respond to the questions and objections even based on false presumptions; it is far enough from the code of good behaviour of the staff of the EU institutions - protecting it from the misused right to be informed.

- A very close relationship between NGOs and public administrations concerning environmental protection that could be deemed to be on the boundary of a conflicts of interests, enabling them to repeatedly put very similar questions and to repeatedly ask for a response in a much broader extent than necessary to write up any topic.

- A greater advantage of baseless complaints is the allowance in publishing information first and based mostly on very old-fashioned myths, e.g., in the case of environmental friendliness of modes of transport.

In the second study we have tried, contrary to the more widespread attitude, not only to calculate the costs of the infrastructure projects and the harmful effects of transport, but also the negative impact of doing nothing - not only on the economy, but even the environmental costs caused by the delayed construction. We have simply ignored the very oversimplified idea that the less transport infrastructure, the better for the society as a whole. As a criterion, we used provisions of the chapter XIX. "Environment" of the Treaty 
of European Communities: - saved fuel, - lower emissions of greenhouse gases influencing climate change, - lower number of accidents, namely fatal accidents per performed vehicle kilometres using motorways and speedways instead of roads of a lower level. We omitted a comparison of the number of accidents according to the modes of transport as a starting position of evaluation; the starting points in our approach are demand for mode of transport, the others have been the specific consumption of fuel (in passenger traffic consumption per passenger) and the specific emissions to prove firstly the environmental efficiency in comparable conditions. The results are:

- A smoother flow of traffic on a quarter of the finished Prague Circle have accelerated the average speed of vehicle by more than twice, according to the test runs, - from less than 40 kilometres per hour to more than 80 kilometres per hour; the lower average speed on the unfinished three quarters of the Prague Circle is mostly caused by an average of nearly 10 stops every quarter, due to traffic signalling or traffic jams in the streets temporary substituting the Prague Circle. The increase in average speed will be higher after the Prague Circle enters full operation as a whole (holistic effects).

- Accordingly, there should be more than a twofold decrease of emissions of greenhouse gases.

- The share of savings accrued to the saved fuel and emissions was, using some global estimates, about $3: 1$, depending very much on the estimates of prices of oil and it is a very difficult task. Now after the approved values of emissions due to the future Directive oriented towards "greener" road vehicles, emissions are priced lower and the rate is about 5:1 in favour of fuel.

\section{ENVIRONMENTAL EFFICIENCY OF LOCAL AND REGIONAL PASSENGER RAILWAY AND ROAD (BUS) TRAFFIC}

There is a myth concerning the generally more environmentally friendly railways and inland waterway transport as opposed to road transport. The environmental friendliness of railways and of goods trafficked using water-borne transport was generally valid in the days when horse carriages were used for road transport as the only competitors of railways in overland transport, and in the case of states with extensive canals. But the limits of efficiency in the period of immense development of transport technology have transformed - development of railway technology however could not change the basic characteristics of this branch of transport - mass transportation. Mass transportation needs, in passenger traffic, enough passengers to transport them in an efficient way, as viewed through energy efficiency, and this is particularly difficult for domestic traffic in such a small territory as the Czech Republic, than at the pan-European level. Naturally, there are many examples of well-organised domestic rail traffic in small territories (Switzerland, Austria or some regions like Bavaria). It is, however, very demanding. We try to find the minimum passengers necessary to reach the least specific consumption per passenger - because a great part of local and regional transport units use vehicles of similar capacity, comparable both in bus and rail transport, and in a similar way, we have tried to find the lower limits of occupation regarding specific emissions. In many comparisons of road and rail for road the direct consumption of road vehicles is considered and the whole consumption of the railway system is considered for rail. In our comparisons, because of diesel traction in the case of local and regional rail transport, there are no problems with the calculations of the compunctions at the level of sources. After having compared these two environmental parameters there is the problem of a satisfactory number of trains meeting the costs of the infrastructure. Therefore, new solutions for the operation of regional infrastructure are necessary (and maybe a field of the research). This means simple signalling systems and adequate operational rules, 
which enable the low-cost operation of low-demand lines, sustainable on account of the possibilities of public subsidies. In case of low-demand for passenger railway transport, there could be the possibility to support a better modal split using some negative impacts in favour of the higher charging of road transport - even passenger mass transport. (But on local and regional lines, with the exception of commuting in large conurbations, the main competitors are cars.). In addition, it is necessary to re-evaluate some of the functions of local and regional railways as historical technological landmarks - with the changing function of railways from predominantly commuting - and therefore with reorientation of usage of its infrastructure in favour of tourism, within the framework of regional activities; with the possibility to improve the productivity of traffic staff adding other, up to now, unusual activities. Because a railway line with 3 pairs of trains per day could hardly employ anybody as a full time worker and full time work in the above mentioned case - and it could be typical for many stretches of local and regional lines only used for traffic operations could not earn money enough to cover costs with only an acceptable level of subsidies. It is therefore necessary to develop innovative solutions for the operation of this infrastructure.

\section{MARGINAL AND FULL COSTS OF TRANSPORT}

After long discussions it was concluded that in the case of transport costs, especially in the case of transport infrastructure, marginal costs should be used instead of full costs. In the case of railway, it could be clear if the more important segment has had enough capacity of transport infrastructure in the railway sector or a part of the other shadow subsidies of railways. It may be that the reaction of greater subsidies in favour of railways as opposed to the necessity to build new infrastructure capacities is that it would be easier and cheaper to remove bottlenecks in the transport network as a whole. Let us now compare in a very simplified form the capacities of typical segments of infrastructure in road and railway transport. We suppose only one lane of motorway or speedway for haulage and a single track railway line for goods traffic. We can suppose that the second or other lane of road is used for other road users (cars, other vehicles). Such a precondition is disadvantageous for road transport and gives the advantage to rail transport. We suppose the unique average speed in both modes of transport to be 85 kilometres per hour. For the railways it is rather a goal for at least next decade rather than a reality. We have taken one kilometre stretch of lane and calculated the necessary occupied part of road for safety traffic: the maximum length of a lorry (semi-trailer unit) is in the Czech Republic $22 \mathrm{~m}$, in case of a speed of 85 kilometres/hour the stopping (braking) distance is about $61.4 \mathrm{~m}$; the total necessary length is 83.4 meters, on one kilometre of carriageway (lane) it is possible to put 1000/83.4 which equals about 12 vehicles. In the case of bad weather or not full braking we have taken the coefficient of adhesion to be 0.4; the braking distance is about $97 \mathrm{~m}$, the necessary segment of carriageway of the lane occupied by one semitrailer unit is $119 \mathrm{~m}$, on one kilometre is possible to drive safely $1000 / 119=8.4$ vehicles. $^{1}$

We suppose that the lorry (semi-trailer unit) with a gross weight of 40 tonnes transports 24 tonnes of goods. In the first case it is possible to transport 288 tonnes, in the second case 201.6 tonnes. In the case of a single track railway line it is necessary to count with the length of blocking stretches for competitive railways with the allowed maximum speed of $100 \mathrm{~km} /$ hour, even if at this time the speed of liners is up to $60 \mathrm{~km} / \mathrm{hour}$; for one train it is necessary to block 3 one kilometre stretches. The gross weight of an average goods train in the year 2007 was 997 tonnes; weight of goods carried is about 50\% - 498.5 tonnes,

\footnotetext{
${ }^{1}$ Calculation of stopping distance computed by I. Drahotský
} 
on one kilometre fall on one third, which means $498.8 / 3=166.2$ tonnes. Contrary to the central command economy and more generally industrial society with a huge output of mining and traffic of coal, construction materials, fertilizers, ores, with a high share of block trains heavier than 2000t gross weight and a lesser weight of liner, where the railway could compete under some other conditions with road transport, the gross weight of liners was about $60 \%$ to $75 \%$ of the average weight of a goods train. Now the maximum gross weight of liners in a range from $100 \%$ to about $125 \%$ gross weight of the average goods train can be estimated. To reach the compatible capacity of the railway under the above mentioned conditions the net weight should be from 604.8 tonnes to 864 tonnes; gross weight should than be doubled - from nearly 1210 tonnes to nearly 1728 tonnes. But the probability of the greater weight of liners in domestic traffic in a society of services based on knowledge and the dominance of craft and small- and medium- sized enterprises is rather low; the capacity of the railway single line track, at least in internal traffic, would probably be much lower. And as we have mentioned that the average speed of $85 \mathrm{~km} / \mathrm{hour}$ is rather a future goal, it is necessary to mention one aspect that handicaps railway transport: the system of the fix length of blocking stretches decreases with the decreasing speed of trains the capacity of railway line. In the case of motorways is it an opposite case: decreased average speed has abbreviated the stopping distance. However a lower speed does not always cause a higher capacity in road traffic. This is to simplify the determination of the limit capacity for the safe movement of vehicles on the road, so that in the case of dangerous situations is possible to stop the vehicle immediately. In terms of the calculation, this is the use of the basic physical relationship for steady movement, equally fast or slow. These are the exact mathematical calculations. Considered is the distance between the vehicles corresponding to the trajectory necessary to stop the vehicle during braking, including reaction time and start of reaction time. The underlying assumption is:

- Response time of driver $1 \mathrm{~s}$

- Time of the start of the braking effect of road freight $0,2 \mathrm{~s}$

- Coefficient of adhesion 0.8 - then $0.8 / 2=0.4$

- Considered road is dry (adhesion coefficient of 0.4 represents half of the value obtainable brake deceleration - the vehicle do not break critically, but ordinary)

Table 1: Mathematical calculations

\begin{tabular}{|c|c|c|c|c|}
\hline Option & 1 & 2 & 3 & 4 \\
\hline Initial speed [km.h-1] & 60 & 60 & 85 & 85 \\
\hline Response time of driver [s] & 1 & 1 & 1 & 1 \\
\hline Rise time of braking effect [s] & 0,2 & 0,2 & 0,2 & 0,2 \\
\hline Coefficient of adhesion [1] & 0,8 & 0,4 & 0,8 & 0,4 \\
\hline $\begin{array}{l}\text { Achievable braking rate } \\
\text { (deceleration) }[\mathrm{m} . \mathrm{s}-2]\end{array}$ & $\begin{array}{l}9,80665 \mathrm{x} \\
0,8=7,845\end{array}$ & $\begin{array}{l}9,80665 \times \\
0,4=3,923\end{array}$ & $\begin{array}{c}9,80665 \times \\
0,8=7,845\end{array}$ & $\begin{array}{l}9,80665 \times \\
0,4=3,923\end{array}$ \\
\hline $\begin{array}{l}\text { Distance necessary to stop the } \\
\text { vehicle (including driver } \\
\text { reaction time) [m] }\end{array}$ & 36 & 53,7 & 61,4 & 97 \\
\hline
\end{tabular}

\section{OCCUPIED LAND}

Concerning the amount of occupied land, railway and road transport are comparable. One of the often-false paroles is a saving of land. We would like to prove it. The total length of the Czech railway network is about $9450 \mathrm{~km}$. On this network, there are 1026 stations open for goods traffic. According to the Railway Act the rail zone is either 30 or 60 meters (without 
yard areas). To follow the text in the previous section we suppose the railway line to have one track; for this purpose it is enough to make the rail zone $30 \mathrm{~m}$ and because of other subconditions it is possible in this rail zone to build another track necessary for the handling of goods or containers in the stations. So it is possible to make as a very global presumption that on one kilometre it is possible to count with a land of about $60000 \mathrm{~m} 2$. According to the Act of ground communications, the protective zone of motorways or speedways are the protective zones of: - motorways and speedways $100 \mathrm{~m}$,

- roads of the first class 50 meters,

- roads of II. and III. class 15 meters.

Because we calculated in the previous section with only one lane, we could in an overestimated case count for this one lane with $15 \mathrm{~m}$ to $30 \mathrm{~m}$ - in the worst case $-30 \mathrm{~m}$. And the ration of used land in railways and roads is very similar to the ratio of capacities in the previous part.

\section{SHORT EPILOGUE}

In course of the completed parts of research work we have found many reasons for revaluating the "classical" doctrines of modal split as a reason to continue in our present work.

\section{REFERENCES}

INFRAS, CE Delft, Fraunhofer Gesellschaft - ISI, University of Gdansk. Handbook of estimation of external costs in the transport sector. Within the study Internalisation Measures and Polices for All external cost of Transport (IMPACT). Version 1.0. Delft December 19th 2007 and 1.1 February 2008.

MRAVČÍKOVÁ, M., ŠMEJKALOVÁ V.:Transport and environment : Attitude of European union. Doprava, Vol. 50, Iss. 6, pp. 13 - 14.

PELTRÁM, A. et al:: Comparison of local and regional railway and road transport from the point of view of incidence on environment and decreased of demand for energy and possibilities to finance from public funds. Part 1 of a grant of Ministry of Transport 2008 .

DRAHOTSKÝ I., PETRÁM A.: Enforcing vehicles with the lower influence on the environment. Doprava, Vol. 50, Iss. 6, pp. 3 - 4.

PELTRÁM A. et al.: „How to increase the awareness of society to investments to transport infrastructure in terms of law of Europeana Union “.

PELTRÁM, A. et al.: The evaluation of the economic impact of delays of construction of selected road communications. Praha: BIVŠ, 2008. 103 pp.

Research project for the Ministry of Tranport of the Czechoslovak Republic: Review of completeness and comparability of costs of railway, road and water borne transport; re-evaluation of the way of counting costs of road infrastructure into the costs of road transport of goods. Praha: Research Institute of Transport, 1965. 